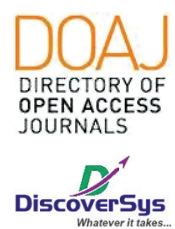

Published by DiscoverSys

\section{Hubungan antara Platelet Lymphocyte Ratio (PLR) dan respon Neoadjuvant Chemotherapy (NAC) CAF pada pasien Locally Advanced Breast Cancer}

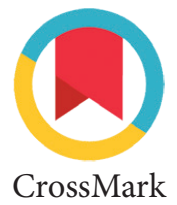

\author{
Aryo Wibisono, ${ }^{1 *}$ I Nengah Wiadnyana Steven Christian, ${ }^{2}$ Putu Anda Tusta Adiputra ${ }^{2}$
}

Background: The incidence of $L A B C$ (Locally Advanced Breast Cancer) in Indonesia is estimated more than 50\%, and in Bali as many as $76.3 \%$ from all of breast cancer cases. Response of NAC (Neoadjuvant chemotherapy) in $L A B C$ case is not the same on each patient. Currently, there are several biomarkers that can be a predictor of NAC response on LABC. One of them is PLR (platelet lymphocyte ratio). PLR is an easy, cheap and fast marker to be counted, but not all clinicians know its role. Lack of research in the relationship of PLR to NAC CAF (Cyclophospamide, Adriamycin, 5 Flourouracil) response in patients with $L A B C$ are currently making researchers interested in studying it.

Method: This research is observational analytics, using a retrospective cohort study. The number of samples was 62 (consecutive sampling), obtained from the medical records of patients who had undergone
NAC CAF from 2015-2019 at Sanglah Hospital Denpasar. PLR value and initial tumor size were calculated before undergoing chemotherapy, then assessed the NAC CAF response to tumors after undergoing 3 cycles of chemotherapy. Positive response if tumor size is reduced and negative response if the tumor size is persists or enlarges. In this study use a cut off point of PLR 150.

Results: From 62 respondents obtained PLR value $\leq 150$ had a positive response of $77.1 \%$ and $22.9 \%$ had a negative response. From these results obtained a correlation between PLR value with responses to NAC CAF in $L A B C$ patients, where low PLR values had positive responses 1.6 times (IK 95; $1.04-2.47$ ) with an output value of $p=0.018$.

Conclusion: There is a correlation between PLR and NAC CAF response, where a low PLR value (PLR $\leq 150)$ has a positive response to NAC CAF in $L A B C$ patients.

Keyword: PLR (Platelet lymphocyte ratio), NAC (Neoadjuvant chemotherapy), CAF (Cyclophospamide, Adriamycin, 5 Flourouracil), LABC (Locally Advanced Breast Cancer).

Cite This Article:Wibisono, A., Christian, I.N.W.S., Adiputra, P.A.T. 2020. Hubungan antara Platelet Lymphocyte Ratio (PLR) dan respon Neoadjuvant Chemotherapy (NAC) CAF pada pasien Locally Advanced Breast Cancer. Intisari Sains Medis 11(2): 647-651. D0I: 10.15562/ism.v11i2.754

\title{
ABSTRAK
}

Latar Belakang: Angka kejadian LABC (Locally Advanced Breast Cancer) di Indonesia diperkirakan lebih dari 50\%, dan di Bali sebanyak $76,3 \%$ dari semua kasus kanker payudara. Respon NAC (neoadjuvant chemotherapy) pada kasus LABC tidak sama pada setiap penderita. Saat ini terdapat beberapa biomarker yang dapat menjadi prediktor terhadap respon NAC pada LABC, salah satunya adalah PLR (platelet lymphocyte ratio). PLR merupakan suatu marker yang mudah, murah dan cepat untuk dinilai tetapi masih banyak klinisi yang belum mengetahui perannya. Kurangnya penelitian mengenai hubungan PLR terhadap respon NAC CAF (Cyclophospamide, Adriamycin, 5 Flourouracil) pada pasien LABC saat ini membuat peneliti tertarik untuk meneliti hal tersebut.

Metode: Jenis penelitian analitik observasional menggunakan studi kohort retrospektif, dengan 62 responden (consecutive sampling), yang didapatkan dari rekam medis pasien yang telah menjalani NAC CAF dari tahun 2015-2019 di RSUP Sanglah Denpasar. Nilai PLR dan ukuran tumor awal dihitung sebelum kemoterapi, kemudian dinilai respon NAC CAF terhadap tumor setelah menjalani 3 siklus kemoterapi. Respon positif yaitu jika terjadi reduksi ukuran tumor $\geq 30 \%$ dari ukuran tumor awal dan respon negatif jika terjadi reduksi ukuran tumor $<30 \%$. Penelitian ini menggunakan cut off point PLR 150,0 yang didapatkan dari penelitian sebelumnya.

Hasil: Dari 62 responden didapatkan nilai PLR $\leq 150$ mempunyai respon positif sebanyak 77,1\% dan 22,9\% respon negatif. Dari hasil tersebut didapatkan hubungan antara nilai PLR dengan respon terhadap NAC CAF pada pasien $L A B C$, dimana nilai PLR rendah mempunyai respon positif sebanyak 1.6 kali (IK 95; $1.04-2.47$ ) dengan hasil output nilai $p=0.018$.

Kesimpulan: Terdapat hubungan antara PLR terhadap respon NAC CAF, dimana nilai PLR yang rendah $(\leq 150)$ mempunyai respon positif terhadap NAC CAF pada pasien LABC.
Departemen IImu Bedah, Fakultas kedokteran Universitas Udayana, RSUP Sanglah Denpasar,Indonesia; aryowibisono@ymail.com

Diterima: 12-05-2019 Disetujui: 03-01-2020 Diterbitkan: 01-08-2020
Kata kunci: PLR (Platelet lymphocyte ratio), NAC (Neoadjuvant chemotherapy), CAF (Cyclophospamide, Adriamycin, 5 Flourouracil), LABC (Locally Advanced Breast (ancer).

Cite Pasal Ini: Wibisono, A., Christian, I.N.W.S., Adiputra, P.A.T. 2020. Hubungan antara Platelet Lymphocyte Ratio (PLR) dan respon Neoadjuvant Chemotherapy (NAC) CAF pada pasien Locally Advanced Breast Cancer. Intisari Sains Medis 11(2): 647-651. D0I: 10.15562/ism.v11i2.754 


\section{PENDAHULUAN}

Locally Advanced Breast Cancer (LABC) adalah kanker payudara lanjut yang belum bermestastasis pada organ lain. ${ }^{1,2}$ Diperkirakan angka kejadian kasus baru LABC pertahun di dunia mencapai 300.000-450.000. Di Indonesia diperkirakan angka kejadian lebih dari 50\% kasus kanker payudara pertahun dan di Bali diperkirakan 76,3\% kasus LABC. ${ }^{3}$

Neoadjuvant chemotherapy (NAC) sebagai standar terapi pada LABC dari berbagai uji klinis menunjukkan hasil dengan respon bervariasi. Pada penelitian ini respon kemoterapi digolongkan menjadi 2 bagian yaitu respon positif (Partial respons dan complete respons) jika terdapat reduksi ukuran tumor $\geq 30 \%$ dan respon negatif (Stable disease dan progresive disease) jika terdapat reduksi ukuran tumor $<30 \%$.

Regimen CAF merupakan kombinasi 3 NAC pada LABC yaitu terdiri dari cyclophospamide, adriamycin dan 5-flourouracil. ${ }^{3-7}$

Saat ini terdapat beberapa biomarker yang dapat menjadi prediktor terhadap respon NAC, salah satunya adalah platelet lymphocyte ratio (PLR). PLR adalah salah satu parameter hematologi yang dapat digunakan untuk mengetahui respon NAC pada pasien dengan kanker payudara. PLR dapat digunakan sebagai indikator untuk mengevaluasi respon inflamasi sistemik pada penderita kanker..$^{8-13}$ Berdasarkan hasil penelitian Asano et al., 2016 (cut off point PLR 150) didapatkan PLR rendah memiliki respon positif terhadap NAC pada pasien LABC. ${ }^{5}$

PLR merupakan suatu marker yang mudah, murah dan cepat untuk dihitung namun masih belum banyak yang mengetahui perannya. Sehingga diharapkan dengan mengetahui nilai PLR, nantinya klinis dapat menjadikan dasar edukasi kepada pasien LABC mengenai prognosis dan prediksi respon kemoterapi. Disamping itu kurangnya penelitian mengenai hubungan PLR terhadap respon NAC pada LABC, dan belum adanya penelitan yang menggunakan regimen CAF membuat peneliti tertarik untuk meneliti hal tersebut.

\section{METODE}

Penelitian ini menggunakan jenis penelitian analitik observasional dengan menggunakan studi kohort retrospektif, dimana variable independen adalah PLR dan variable dependen adalah respon NAC. Beberapa variabel perancu yaitu usia, status reseptor hormonal, ekpresi Her 2/Ki67. Langkah pengendalian dengan cara randomisasi sampel.

Penelitian ini dilakukan di RSUP Sanglah Denpasar, Bali, dari bulan Januari 2019 hingga Juli 2019 dengan total sampel 62 orang. Sampel penelitian diperoleh dari rekam medis pasien RSUP Sanglah Denpasar yang menjalani NAC CAF dari tahun 2015-2019. Penentuan sampel dilakukan secara consecutive sampling. Populasi target pada penelitian ini adalah pasien LABC di RSUP Sanglah Denpasar dengan pupulasi terjangkau adalah pasien LABC di RSUP Sanglah Denpasar yang menjalani NAC menggunakan regimen CAF dari tahun 2015-2019. PLR didapatkan dari hasil pemeriksaan di laboratorium patologi klinik RSUP Sanglah sebelum menjalani NAC CAF (5-7 hari sebelum kemoterapi). Niai PLR didapatkan dengan cara jumlah platelet dibagi dengan nilai limfosit absolut. Cut off point PLR pada penelitian ini mengikuti penelitian yang dilakukan oleh Asano et al yaitu 150. PLR $\leq 150$ adalah rendah, dan PLR $>150$ adalah tinggi. ${ }^{5}$

Dilakukan pencatatan ukuran tumor awal yang telah tercacat di rekam medis dengan dimensi tumor yaitu panjang dan lebar. Kemudian dinilai respon NAC CAF setelah menjalani 3 siklus kemoterapi.

Dilakukan pencatatan kembali ukuran tumor setelah dilakukan kemoterapi NAC CAF 3 siklus (5-7 hari), kemudian dilihat respon klinis dengan membandingkan ukuran tumor awal dengan ukuran tumor setelah kemoterapi.

Respon klinis didapatkan dengan cara ukuran tumor awal dikurang ukuran tumor setelah kemoterapi dibagi ukuran tumor awal, kemudian dikali $100 \%$. Respon positif yaitu jika terjadi reduksi ukuran tumor $\geq 30 \%$ dari ukuran tumor awal dan respon negatif jika terjadi reduksi ukuran tumor $<30 \%$ dari ukuran tumor awal.

Kriteria inklusi adalah pasien wanita dengan $\angle A B C$ dengan tipe histopatologis invasif non special type (NST), pasien yang telah menjalani NAC menggunakan regimen CAF sebanyak 3 siklus, mempunyai data rekam medis yang terdokumentasi secara detail dan akurat (hasil laboratorium, biopsi payudara, USG mamme, USG axila, USG liver dan foto rontgen thoraks).

Kriteria eksklusi adalah pasien mempunyai riwayat penyakit komorbid yang berat seperti penyakit gangguan perdarahan, penyakit infeksi, diabetes melitus, penyakit ginjal, penyakit liver dan penyakit immune compromised yang dilihat dari data rekam medis. Pasien meninggal dunia dalam periode siklus kemoterapi neoadjuvan, pasien menjalani kemoterapi neoadjuvan kurang dari 3 siklus dan data rekam medis pasien tidak lengkap dikeluarkan dari penelitian ini.

Teknik analisis data yang dilakukan pada penelitian ini adalah analisis univariat dan bivariat. Analisis univariat dilakukan untuk menggambarkan karekteristik (umur, ukuran tumor, keterlibatan node, hasil patologi anatomi dan nilai PLR dalam 
bentuk table distribusi frekuensi, persentase, mean dan standar deviasi untuk variable yang berskala numerik. Analisis bivariat dilakukan dengan menggunakan uji chi-square. Analisis chi-square dilakukan guna mendapatkan 95\% confidence interval dan nilai $\mathrm{p}$ ( $\mathrm{p}$-value). Nilai $\mathrm{P}<0,05$ menunjukkan bahwa terdapat hubungan yang bermakna secara statistik antara PLR dan respon NAC CAF. Data yang tekumpul dari rekam medis yaitu sebanyak 62 responden akan dianalisis melalui uji hipotesis Chi Square kemudian dilakukan penghitungan terhadap risiko relatif (RR), dimana $R R>1$ maka PLR tinggi menurunkan respon NAC, $R R<1$ maka PLR rendah meningkatkan respon NAC, dan $R R=1$ maka PLR tidak berhubungan dengan respon NAC.

Pengujian terhadap hipotesis yang menyatakan adanya hubungan antara PLR yang rendah mempunyai respon positif terhadap NAC pada LABC dilakukan dengan bantuan program SPSS statistics for windows, version 25 .

\section{HASIL}

Gambaran karakteristik sampel penelitian seperti yang digambarkan di table 1. Berdasarkan usia didapatkan rata-rata usia adalah 48,64 tahun dengan rentang usia 32-63 tahun. Berdasarkan karakteristik ukuran tumor awal (T), T4 mendominasi sebesar $74,2 \%$. Berdasarkan karakteristik keterlibatan node (N), N1 mendominasi sebesar 67,7\%. Berdasarkan karakteristik hasil patologi anatomi, invasive of NST grade 2 mendominasi sebesar 53.2\%. Berdasarkan karakteristik hasil subtipe, luminal B mendominasi sebesar 40.3\%, Berdasarkan karakteristik nilai PLR, PLR rendah mendominasi sebesar 56.5\%. Data deskriptif mengenai karakteristik sampel penelitian dapat dilihat pada tabel dibawah (tabel 1).

Dari analisa bivariat didapatkan bahwa jumlah responden yang mempunyai nilai $\mathrm{PLR} \leq 150$ dengan respon NAC CAF positif sebanyak 27 responden, sedangkan respon negatif sebanyak 8 responden. Jumlah responden yang mempunyai nilai PLR $>150$ dengan respon NAC CAF positif sebanyak 13 responden sedangkan respon negatif 14 responden.

Dari hasil perhitungan uji hipotesis Chi-Square didapatkan bahwa nilai PLR rendah mempunyai respon positif terhadap NAC pada LABC sebanyak 1.6 kali (IK 95; 1.04 - 2.47) dengan hasil output nilai $\mathrm{p}=0.018$. Nilai $\mathrm{p}$ yang lebih kecil dari 0.05 menyebabkan Ho dalam penelitian ini ditolak.

Tabel 1 Karakteristik Sampel Penelitian

\begin{tabular}{|c|c|c|c|c|}
\hline \multirow[b]{2}{*}{ Variabel } & \multicolumn{2}{|c|}{ Respon kemoterapi } & \multirow[b]{2}{*}{ Total } & \multirow[b]{2}{*}{ P value } \\
\hline & Positif & Negatif & & \\
\hline \multicolumn{5}{|l|}{ Usia (\%) } \\
\hline$\leq 45$ tahun & $20(50,0)$ & $10(45,5)$ & $30(48,4)$ & 0,732 \\
\hline$>45$ tahun & $20(50, \mathrm{o} 0)$ & $12(54,5)$ & $32(51,6)$ & \\
\hline \multicolumn{5}{|l|}{ Ukuran Tumor awal (\%) } \\
\hline $\mathrm{T} 3$ & $12(30,0)$ & $4(18,2)$ & $16(25,8)$ & 0,309 \\
\hline $\mathrm{T} 4$ & $28(70,0)$ & $18(81,8)$ & $46(74,2)$ & \\
\hline \multicolumn{5}{|l|}{ Keterlibatan Node (\%) } \\
\hline No & $2(5,0)$ & $1(4,5)$ & $3(4,8)$ & 0,502 \\
\hline N1 & $29(72,5)$ & $13(59,1)$ & $42(67,7)$ & \\
\hline N2 & $9(22,5)$ & $8(36,4)$ & $17(27,4)$ & \\
\hline \multicolumn{5}{|l|}{ Hasil Patologi Anatomi (\%) } \\
\hline Invasive of NST grade 1 & $2(5,0)$ & $1(4,5)$ & $3(4,8)$ & 0,987 \\
\hline Invasive of NST grade 2 & $21(52,5)$ & $12(54,5)$ & $33(53,2)$ & \\
\hline Invasive of NST grade 3 & $17(42,5)$ & $9(40,9)$ & $26(41,9)$ & \\
\hline \multicolumn{5}{|l|}{ Subtipe (\%) } \\
\hline Luminal A & $4(7,5)$ & $5(18,2)$ & $9(11,3)$ & 0,596 \\
\hline Luminal B & $17(40,0)$ & $9(40,9)$ & $26(40,3)$ & \\
\hline Her2 type & $8(20,0)$ & $3(13,6)$ & $11(17,76)$ & \\
\hline TNBC & $11(32,5)$ & $5(27,3)$ & $16(30,6)$ & \\
\hline \multicolumn{5}{|l|}{ Nilai PLR (\%) } \\
\hline$<150$ & $27(67,5)$ & $8(36,4)$ & $35(56,5)$ & 0,018 \\
\hline$>150$ & $13(32,5)$ & $14(63,6)$ & $27(43,5)$ & \\
\hline
\end{tabular}




\section{PEMBAHASAN}

Dengan menganalisis data hemogram (limfosit neutrofil, monosit, dan jumlah trombosit), banyak penelitian telah melaporkan peran respon imun sebagai faktor prognostik dari perkembangan tumor. Sel-sel tumor telah terbukti menginduksi sintesis platelet stimulating factor yang mendukung pertumbuhan, invasi dan metastasis tumor primer oleh beberapa mekanisme. ${ }^{14-17}$

Tumor microenvironment sangat mempengaruhi sel-sel kanker dan berkontribusi pada pembentukan karakteristik khusus untuk kanker. Oleh karena itu, pemantauan pada lingkungan mikro tumor inang sangat penting dalam memprediksi respon terapi dan prognosis. Indikator inflamasi sistematik, seperti PLR, telah dilaporkan sebagai marker untuk memantau lingkungan mikro tumor inang. ${ }^{18,19}$ Sel tumor berikatan dengan platelet dan membentuk coating agar tidak dapat terdeteksi oleh sistem imun. Angiogenesis adalah tahap yang sangat penting bagi pertumbuhan, perkembangan, dan metastasis kanker. Vascular endothelial growth factor (VEGF) yang dikenal sebagai stimulator poten untuk angiogenesis dan sumber produksi VEGF adalah platelet.

Proses proliferasi sel, khususnya proliferasi otonom, penting untuk menjelaskan mekanisme karsinogenesis, karena faktor pertumbuhan dan reseptornya terkait erat untuk gen kanker. Faktor pertumbuhan turunan trombosit termasuk PDGF, TGF- $\beta$ dan PD-ECGF, yang terlibat dalam perbaikan dan regenerasi jaringan. PDGF memiliki struktur yang mirip dengan protein yang membentuk gen kanker sis, dan struktur tirosin kinase yang ada pada reseptor PDGF yang ditemukan pada beberapa gen kanker. Terlebih PDGF menginduksi gen kanker seperti myc dan fos, yang ada di inti sel. Hal ini menunjukkan bahwa kelainan yang terjadi dalam proses aktivasi faktor pertumbuhan terkait dengan kanker sel. ${ }^{15}$ TGF- $\beta$ bekerja untuk menghambat kanker melalui aktivitas sitostatik di awal tahapan karsinogenesis, namun, sebaliknya berfungsi untuk mempromosikan kanker pada tahap perkembangan kanker selanjutnya. ${ }^{16}$ Faktor pertumbuhan turunan trombosit sering dibuat dalam jumlah besar oleh sel kanker dan memiliki efek pada histologi kanker. ${ }^{15,16,20}$ Mereka telah ditemukan berkontribusi untuk dalam hal metastasis, invasi dan pertumbuhan tumor primer. Dengan demikian jumlah trombosit darah tepi dapat dijadikan indikator aktivitas tumor.

Sementara itu, limfosit bertanggung jawab untuk kekebalan tubuh dan respon terhadap pertumbuhan tumor. Dengan demikian jumlah limfosit darah perifer dianggap sebagai indikasi untuk penekanan tumor. Sehingga dapat diartikan bahwa pasien dalam kelompok PLR rendah dengan jumlah trombosit yang rendah dan jumlah limfosit yang tinggi menunjukkan aktivitas antitumor yang tinggi dan berkorelasi dengan prognosis yang baik dan sensitivitas kemoterapi.

Mekanisme dimana PLR dan sensitivitas kemoterapi mempunyai korelasi terjadi adalah sebagai berikut. Trombosit adalah sel yang mengandung jumlah terbesar dari faktor pertumbuhan, dan jumlah trombosit merupakan indikator aktivitas kanker. Jumlah trombosit yang rendah menunjukkan sel kanker dengan aktivitas rendah. Kemoterapi meningkatkan myelosupresi dan menurunkan jumlah trombosit. Selanjutnya, kemoterapi meningkatkan jumlah limfosit dengan mengaktifkan respons imun. Hal ini dianggap dapat menurunkan PLR dan meningkatkan efek antitumor.

Pada penelitian Asano $Y$ et al.,2016 menyebutkan PLR tinggi (>150) mempunyai prognostik yang kurang baik $(\mathrm{p}=0.005$, hazard ratio $=2.84) .{ }^{5}$ Pada penelitian Lopez et al. juga menyebutkan respon NAC terhadap pathological complete respon secara signifikan lebih tinggi pada kelompok PLR rendah (35.1\% Vs $22.2 \%, \mathrm{p}=0.03) .{ }^{13}$ Begitu juga pada penelitian Rafee, et al., PLR tinggi (>138.19) secara independen terkait dengan respon yang buruk terhadap kemoterapi neoadjuvant pada kanker payudara. ${ }^{12}$ Penelitian kami juga menunjukkan hal yang sama yaitu PLR rendah $(\leq 150)$ mencapai respon positif setelah NAC CAF lebih tinggi $(67,5 \%$ vs $32,5 \%$, $\mathrm{p}=0.018$.) Secara keseluruhan, data ini mendukung peran PLR sebagai variabel prediktif terhadap respon NAC CAF terlepas dari variabel usia, ukuran tumor primer, keterlibatan node, grading histologi patologi anatomi maupun subtipe molekul tumor.

Namun penelitian ini mempunyai beberapa kelemahan yaitu jumlah responden yang digunakan minimal, menggunakan data sekunder dari rekam medis pasien menggunakan kohort retrospektif, cut off point yang digunakan menggunakan penelitian sebelumnya, dan penelitian ini hanya dilakukan pada satu institusi saja tanpa melibatkan multicentre yang lain.

\section{SIMPULAN}

Terdapat hubungan antara PLR terhadap respon NAC CAF pada pasien LABC, dimana PLR rendah $(\mathrm{PLR} \leq 150)$ mempunyai respon positif terhadap NAC CAF pada pasien LABC sebanyak $1.6 \mathrm{kali}$ lebih besar dibandingkan dengan PLR yang tinggi $($ PLR $>150)$, Sehingga PLR bisa dapat dijadikan prediktor marker yang andal, murah dan cepat untuk menilai respon NAC CAF sebelum dilakukan kemoterapi. 


\section{KONFLIK KEPENTINGAN}

Tidak ada konflik kepentingan dalam penulisan penelitian ini.

\section{ETIKA PENELITIAN}

Persetujuan etik telah didapat dari komisi etik, Fakultas Kedokteran, Universitas Udayana, RSUP Sanglah, Bali, Indonesia sebelum penelitian ini berjalan dengan nomor ethical penelitian 115/UN 14.2.2.VII.14/LP/2019.

\section{PENDANAAN}

Penulis bertanggung jawab penuh terhadap pendanaan penelitian ini tanpa melibatkan pihak lain.

\section{LAIN-LAIN}

Pada penyusunan penelitian ini saya dibimbing oleh dr. I Nengah Wiadnyana Steven Christian SpB(K)Onk sebagai pembimbing 1 dan dr. Putu Anda Tusta Adiputra SpB(K)Onk sebagai pembimbing 2 .

\section{DAFTAR PUSTAKA}

1. Giordano SH. Update on Locally Advanced Breast Cancer. The Oncologist. 2003;8(6):521-530. doi:10.1634/ theoncologist.8-6-521.

2. Costa R, Hansen N, Gradishar WJ. Locally Advanced Breast Cancer. In the breast: Comprehensive management of benign and malignant disease. Elsevier. 2018;6:819-831. https://doi.org/10.1016/B978-0-323-35955-9.00063-5.

3. Manuaba TW. Panduan Penatalaksanaan Kanker Payudara. Panduan Penatalaksanaan Kanker Solid. PERABOI. Sagung Seto. 2010; 1:18- 50.

4. Bamal R, Chintamani, Tandon M., Mittal, et al. Evaluation and Validation of Neo-Adjuvant Response Index (NRI) and It's Correlation with Various Predictive Biomarkers and RECIST in Locally Advanced Breast Cancer. Indian Journal of Surgical Oncology. 2014; 5(3):171-177. doi:10.1007/s13193-014-0336-1.

5. Asano Y, Kashiwagi S, Onoda N, et al. Platelet Lymphocyte Ratio as a Useful Predictor of the Therapeutic Effect of Neoadjuvant Chemotherapy in Breast Cancer. Plos One. 2016; 11:7.

6. Luangdilok S, Samarnthai N, Korphaisarn $\mathrm{K}$ et al. Association between Pathological Complete Response and Outcome Following Neoadjuvant Chemotherapy in Locally Advanced Breast Cancer Patients. Journal of Breast Cancer. 2014; 17(4):376.doi:10.4048/jbc.2014.17.4.376.

7. Singh J, Singh B, Joneja A, et al. Role of Neoadjuvant Chemotherapy with Cyclophosphamide, Adriamycin, 5-Fluorouracil (CAF Regimen) in Down Staging in Breast Cancer. Annals of International medical and Dental Research. 2016;2:6. doi:10.21276/aimdr.2016.2.6.sg7.

8. Gonzales AM, Hortobagyi G N. Neoadjuvant Systemic Therapy for Breast Cancer. Breast Surgical Techniques and Interdisciplinary Management. 2010; 731-739.
9. Angahar LT. An Overview of Breast Cancer Epidemiology, Risk Factors, Pathophysiology, and Cancer Risks Reduction. MOJ Biology and Medicine. 2017;1:4. doi:10.15406/mojbm.2017.01.00019.

10. Bufi E, Belli P, Costantini M, et al. Role of the Apparent Diffusion Coefficient in the Prediction of Response to Neoadjuvant Chemotherapy in Patients With Locally Advanced Breast Cancer. Clinical Breast Cancer. 2015; 15: 370-380. doi:10.1016/j.clbc.2015.02.002.

11. Kwan HL, Eun YK, Ji SY, et al.The prognostic and predicyive value of tumor infiltrating lymphocytes and hematologic parameters in patients with breast cancer. BMC Cancer. 2018;18:938. https://doi.org/10.1186/s12885-018-4832-5.

12. Zhu Y, Si W, Sun Q, et al. Platelet-lymphocyte ratio acts as an indicator of poor prognosis in patients with breast cancer. Oncotarget. 2016; 8 (1):1023-1030.doi:10.18632/ oncotarget.13714.

13. Lopez J, Zapata A, Agudelo L, et al. Platelet Lymphocyte Ratio as a Useful Predictor of the Therapeutic Effect of Neoadjuvant Chemotherapy in Breast Cancer. PLOS ONE. 2018;13-11.

14. Chua W, Charles KA, Baracos VE, Clarke SJ. Neutrophil/ lymphocyte ratio predicts chemotherapy outcomes in patients with advanced colorectal cancer. British journal of cancer. 2011; 104(8):1288-95. Epub 2011/03/31. https:// doi.org/10.1038/bjc.2011.100 PMID: 21448173; PubMed Central PMCID: PMC3078587.

15. Ohno Y, Nakashima J, Ohori M, et al. Pretreatment neutrophil to lymphocyte ratio as an independent predictor of recurrence in patients with nonmetastatic renal cell carcinoma. The Journal of urology. 2010; 184(3):873-8. Epub2010/07/21. https://doi.org/10.1016/j. juro.2010.05.028 PMID: 20643463.

16. Schmidt H, Suciu S, Punt CJ, et al. Pretreatment levels of peripheral neutrophils and leukocytes as independent predictors of overall survival in patients with American Joint Committee on Cancer Stage IV Melanoma: results of the EORTC 18951 Biochemotherapy Trial. Journal of clinical oncology: official journal of the American Society of Clinical Oncology. 2007; 25(12):1562-9. Epub 2007/04/20. https:// doi.org/10.1200/JCO.2006.09.0274 PMID: 17443000.

17. Azab B, Bhatt VR, Phookan J, et al. Usefulness of the neutrophil to lymphocyte ratio in predicting short- and longterm mortality in breast cancer patients. Annals of surgical oncology. 2012;19(1):217-24. Epub 2011/06/04. https:// doi.org/10.1245/s10434-011-1814-0 PMID: 21638095.

18. Tung NM, Winer EP. Tumor-infiltrating lymphocytes and response to platinum in triple-negative breast cancer. Journal of clinical oncology: official journal of the American Society of Clinical Oncology. 2015;33(9):969-71. https:// doi.org/10.1200/JCO.2014.59.6031 PMID: 25559817.

19. Yu X, Zhang Z, Wang Z, et al. Prognostic and predictive value of tumor-infiltrating lymphocytes in breast cancer: a systematic review and meta-analysis. Clinical \& translational oncology: official publication of the Federation of Spanish Oncology Societies and of the National Cancer Institute of Mexico. 2016; 18(5):497-506. https://doi. org/10.1007/s12094-015-1391-y PMID: 26459255; PubMed Central PMCID: PMCPMC4823351.

20. Eren Tulay, Karacin Cengiz, Ucar gokhan,et al. Correlation between peripheral blood inflammatory indicators and pathologic complete response to neoadjuvant chemotherapy in locally advance breast cancer patients. Medicine. 2020;99:22. doi:10.1097/MD.0000000000020346.

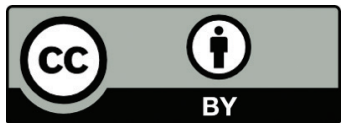

This work is licensed under a Creative Commons Attribution 